\title{
Environmental Ethics for Business Sustainability
}

\author{
Laszlo Zsolnai \\ Business Ethics Center \\ Corvinus University of Budapest \\ Budapest, Fővámtér 8 \\ 1093 Hungary \\ laszlo_zsolnai@interware.hu
}

The paper was written as part of the research project of the Corvinus University of Budapest "Társadalmi Megújulás Operatív Program" TÁMOP-4-2.1.B-09/1/KMR- 20100005 


\title{
Environmental Ethics for Business Sustainability
}

\begin{abstract}
:
The paper derives operational principles from environmental ethics for business organizations in order to achieve sustainability. Business affects the natural environment at different levels. Individual biological creatures are affected by business via hunting, fishing, agriculture, animal testing, etc. Natural ecosystems are affected by business via mining, regulating rivers, building, polluting the air, water and land, etc. The Earth as a whole is affected by business via exterminating species, contributing to climate change, etc. Business has a natural, non-reciprocal responsibility toward natural beings affected by its functioning. At the level of individual biological creatures, awareness-based ethics is adequate for business. It implies that business should assure natural life conditions and painless existence for animals and other sentient beings. From this point of view a business activity system can be considered acceptable only if its aggregate impact on animal welfare is non-negative. At the level of natural ecosystems, ecosystem ethics is relevant for business. It implies that business should use natural ecosystems in a proper way, that is, not damaging the health of the ecosystem during use. From this point of view a business activity system can be considered acceptable only if its aggregate impact on ecosystem health is non-negative. At the level of the Earth as a whole, Gaian ethics applies to business. Its implication is that business should not contribute to the violation of the systemic patterns and global mechanisms of the Earth. From this point of view a business activity system can be considered acceptable only if its aggregate impact on the living planet is non-negative. Satisfying the above principles can assure business sustainability in an ethically meaningful way. In this case business performs its duty: not to harm nature or allow others to come to harm.
\end{abstract}

Keywords: environmental responsibility, animal welfare, ecosystem health, the living planet, aggregate impact of business on nature 
The underlying principle of environmental ethics is that nature has intrinsic value. This means that nature and its parts are not merely means for accomplishing one's purposes but are ends in and for themselves. This statement can be called "the categorical imperative of ecology". The theory of autopoiesis developed by Chilean biologists Humberto Maturana and Francisco Varela supports this position. (Maturana \& Varela 1987)

The term autopoiesis was presented as a description to define and explain the nature of living systems. A canonical example of an autopoietic system is the biological cell. The eukaryotic cell, for example, is made of various biochemical components such as nucleic acids and proteins, and is organized into bounded structures such as the cell nucleus, various organelles, a cell membrane and cytoskeleton. These structures, based on an external flow of molecules and energy, produce the components which, in turn, continue to maintain the organized bounded structure that gives rise to these components.

An autopoietic system is autonomous and operationally closed, in the sense that there are sufficient processes within it to maintain the whole. Autopoietic systems are structurally coupled with their medium, embedded in a dynamic of changes which is considered as at least a rudimentary form of cognition and can be observed throughout life-forms.

\section{BUSINESS' RESPONSIBILITY FOR NATURE}

In contrast with autopoietic systems of nature, business organizations are allopoietic systems. They uses raw materials (components) to generate a products (an organized structure) which are something other than themselves. 
Business affects the natural environment at different levels of the organization of nature. (Zsolnai 1996)

(I) Individual biological creatures are affected by business via hunting, fishing, agriculture, animal testing, etc.

(II) Natural ecosystems are affected by business via mining, regulating rivers, building, polluting the air, water and land, etc.

(III) The Earth as a whole is affected by business via exterminating species, contributing to climate change, etc.

In his opus magnum "The Idea of Responsibility" Hans Jonas argues for a new kind of ethics appropriate in our technological age. The major theses on which Jonas' theory of responsibility is based are as follows: (i) "The altered, always enlarged nature of human action, with the magnitude and novelty of its works and their impact on man's global future." (ii) "Responsibility is a correlate of power and must be commensurate with the latter's scope and that of its exercise." (iii) “An imaginative 'heuristics of fear', replacing the former projections of hope, must tell us what is possibly at stake and what we must beware of." (iv) "Metaphysics must underpin ethics. Hence, a speculative attempt is made at such an underpinning of man's duties toward himself, his distant posterity, and the plenitude of life under his dominion." (v) "Objective imperatives for man in the scheme of things enable us to discriminate between legitimate and illegitimate goal-settings to our Promethean power" (Jonas 1984: x). 
Jonas argues that the nature of human action has changed so dramatically in our times that it calls for a radical change in ethics as well. He emphasizes that in previous ethics, all dealing with the nonhuman world was ethically neutral. Ethical significance belonged to the direct dealing of man with man, including man dealing with himself: all traditional ethics is anthropocentric. The effective range of action was small, the time span of foresight, goal-setting, and accountability was short, control of circumstances limited (Jonas 1984: 4-5).

According to Jonas new dimensions of responsibility emerged because nature became a subject of human responsibility. This is underlined by the fact of the irreversibility and cumulative character of man's impact on the living world. Knowledge, under these circumstances, is a prime duty of man and must be commensurate with the causal scale of human action. Man should seek "not only the human good but also the good of things extra human, that is, to extend the recognition of 'ends in themselves' beyond the sphere of man and make the human good include the care of them" (Jonas 1984: 7-8).

For Jonas an imperative responding to the new type of human action might run like this, "Act so that the effects of your action are compatible with the permanence of genuine human life," Or, expressed negatively, "Act so that the effects of your action are not destructive of the future possibility of such life" (Jonas 1984: 11).

Our duties to nature are independent of any idea of a right or reciprocity. Jonas states that human responsibility is basically a nonreciprocal duty to guard beings (Jonas 1984: 3839). 
Jonas argues for an objectivity of values regarding the purposefulness of living beings: Nature, by entertaining ends, or having aims, as we now assume her to do, also posits values. For with any de facto pursued end attainment of it becomes a good, and frustration of it, an evil; and with this distinction the attributability of value begins. We can regard the mere capacity to have any purposes at all as a good-in-itself, of which we grasp with the intuitive certainty that it is infinitely superior to any purposelessness of being (Jonas 1984: 79-80).

Jonas states that the necessary conditions of moral responsibility are as follows: "The first and most general condition of responsibility is causal power, that is, that acting makes an impact on the world; the second, that such acting is under the agent's control; and the third, that he can foresee its consequences to some extent" (Jonas 1984: 90).

Jonas differentiates between natural responsibility on the one hand and contractual responsibility on the other: "It is the distinction between natural responsibility, where the immanent 'ought-to-be' of the object claims its agent a priori and quite unilaterally, and contracted or appointed responsibility, which is conditional a posteriori upon the fact and the terms of the relationship actually entered into" (Jonas 1984: 95).

Based on the arguments of Jonas we can say that business has a natural, non-reciprocal responsibility toward natural beings affected by its functioning. The responsibility of business toward the natural environment can be summarized as follows: business may not harm nature or allow others to come to harm. 


\section{AWARENNES-BASED ETHICS}

At the level of individual biological creatures the so-called awareness-based ethics is adequate for business. The most eloquent protagonist of this branch of environmental ethics is Australian philosopher Peter Singer. He says: "If a being suffers there can be no moral justification for refusing to take this suffering into consideration." (Fox 1990)

Singer's influential book "Animal Liberation" is an expansion of the utilitarian idea that 'the greatest good of the greatest number' is the only measure of good or ethical behavior. (Singer 1975) He argued that the interests of animals should be considered because of their ability to feel suffering and that the idea of rights was not necessary in order to consider them.

Singer is against what he calls speciesism: discrimination on the grounds that a being belongs to a certain species. He holds the interests of all beings capable of suffering to be worthy of equal consideration, and that giving lesser consideration to beings based on their species is no more justified than discrimination based on skin color. Singer does not specifically contend that we ought not use animals for food insofar as they are raised and killed in a way that actively avoids the inflicting of pain, but as such farms are uncommon, he concludes that the most practical solution is to adopt a vegetarian or vegan diet. Singer also condemns vivisection except where the benefit (in terms of improved medical treatment) outweighs the harm done to the animals used.

From awareness-based ethics a major ethical implication can be derived for business. 
(E1) Business should assure natural life conditions and painless existence for animals and other sentient beings.

Systematic concern for animal welfare is based on the belief that non-human animals are sentient and that consideration should be given to their well-being, especially when they are used for food or in animal testing.

The guidelines for animal welfare has been elaborated including (i) freedom from thirst and hunger - by ready access to fresh water and a diet to maintain full health and vigor, (ii) freedom from discomfort - by providing an appropriate environment including shelter and a comfortable resting area, (iii) freedom from pain, injury, and disease - by prevention or rapid diagnosis and treatment, (iv) freedom to express normal behavior - by providing sufficient space, proper facilities and company of the animal's own kind, and (v) freedom from fear and distress - by ensuring conditions and treatment which avoid mental suffering. (Five Freedoms 2010)

Concern for farm animals is mainly focused on factory farming, where farm animals are raised in confinement at high stocking density. Issues revolve around the limiting of natural behavior in animals (see battery cage, veal and gestation crate), and invasive procedures such as debeaking and mulesing. Other issues include methods of animal slaughter, especially ritual slaughter. While the killing of animals need not necessarily involve suffering, the general public considers killing an animal an act that reduces its welfare. This leads to concerns with premature slaughtering, such as the chick culling. This applies in a lesser extent to all food animals. 
In animal testing, the well-being of individual animals tend to be overridden by the potential benefits their sacrifice can bring to a large number of other animals or people. This utilitarian approach might allow intense suffering to be inflicted on individual animals if the trade-off is considered worthwhile, while a more welfare-based approach would afford all animals the right to a minimum standard of welfare. Other welfare issues includes the quality of animal sources and housing conditions.

Let $\mathbf{B}$ be the activity system of a business organization. Let $\mathbf{A 1}, \ldots, \mathbf{A} \mathbf{j}, \ldots, \mathbf{A n}$ be animal welfare indicators. $(\mathbf{n}>\mathbf{1})$

Ai( ) is an animal welfare function defined as follows:

1 if business activity system $\mathbf{B}$ is good regarding animal welfare indicator $\mathbf{A j}$;

(1) $\mathbf{A j}(\mathbf{B})=\mathbf{0}$ if business activity system $\mathbf{B}$ is neutral regarding animal welfare indicator $\mathbf{A j}$;

$\mathbf{- 2}$ if business activity system $\mathbf{B}$ is bad regarding animal welfare indicator $\mathbf{A} \mathbf{j}$.

$\mathbf{A i}(\mathbf{B})$ reflects the value of the business activity system $\mathbf{B}$ regarding animal welfare indicator $\mathbf{A j}$.

The following vector represents the value of the business activity system $\mathbf{B}$ regarding all the animal welfare indicators $\mathbf{A 1}, \ldots, \mathbf{A j}, \ldots . ., \mathbf{A n}$.

$$
\underline{\mathbf{A}}(\mathbf{B})=[\mathbf{A 1}(\mathbf{B}), \ldots, \mathbf{A j}(\mathbf{B}), \ldots, \mathbf{A n}(\mathbf{B})]
$$

To get an aggregate picture about the value of a business activity system from the animal welfare point of view we should define weights that show the importance of the animal welfare indicators. Let $\mathbf{a 1}, . . ., \mathbf{a j}, . . .$, an be such importance weights. 
It is required that

(3) $\quad \sum$ aj $=1$

The aggregate value of the business activity system $\mathbf{B}$ from the animal welfare point of view can be calculated as follows:

(4) $\quad \mathbf{A}(B)=\sum$ aj $\mathbf{A j}(B)$

A(B) shows the aggregate value of the business activity system $\mathbf{B}$ from the animal welfare point of view. $(1 \geq \mathbf{A}(\mathbf{B}) \geq-2)$

A business activity system can be considered acceptable if and only if its aggregate impact on animal welfare is non-negative. That is

(5) $\quad \mathbf{A}(\mathbf{B}) \geq \mathbf{0}$

\section{ECOSYSTEM ETHICS}

At the level of natural ecosystems the so-called ecosystem ethics is relevant for business.

The maxim of ecosystem ethics was first stated by American environmentalist Aldo Leopold in his classic "Sand County Almanac". He writes: "A thing is right when it tends to preserve the integrity, stability, and beauty of the biotic community. It is wrong when it tends to otherwise." (Fox 1990) Leopold also describes his position in this way: "The land ethic simply enlarges the boundaries of the community to include soils, waters, plants, and animals, or collectively: the land. A land ethic changes the role of Homo sapiens from conqueror of the land-community to plain member and citizen of it. It implies respect for his fellow-members, and also respect for the community as such." (Leopold 1949) 
Ecosystem ethics implies non-declining natural wealth. In more exact terms it requires that the ecological value of the natural ecosystems be not decreasing over time.

Robert Constanza proposed ecosystem health as an operationalized measure of ecological value. It is defined as follows:

$H I=V \times O \times R$

where $H I$ is ecosystem health index; $V$ is ecosystem vigor, a cardinal measure of system activity, metabolism, or primary productivity; $O$ is ecosystem organization index, a $0-1$ index of the relative degree of the system's organization, including its diversity and complexity; and $R$ is ecosystem resilience index, a $0-1$ index of the relative degree of the system's resilience. In essence, in calculating $H I$ the ecosystem's primary production is weighted by indices for relative organization and resilience. In this context, eutrophication is unhealthy since it usually represents an increase in metabolism that is more than outweighed by a decrease in organization and resilience. Artificial eutrophic systems tend toward lower species diversity, shorter food chains, and lower resilience. (Constanza 1992)

Ecosystem ethics requires that business organizations interact with the ecosystem in a way that the health of the ecosystem is not damaged. From ecosystem ethics the following ethical implication can be derived for business. 
(E2) Business should use natural ecosystems in a proper way, that is, not damaging the health of the ecosystem during use.

Let $\mathbf{E} 1, \ldots, \mathbf{E j}, \ldots, \mathbf{E n}$ be ecosystem health indicators. $(\mathbf{n}>\mathbf{1})$

Ei( ) is an ecosystem health function defined as follows:

1 if business activity system $\mathbf{B}$ is good regarding ecosystem health indicator $\mathbf{E j}$;

(6) $\mathbf{E j}(\mathbf{B})=\quad \mathbf{0}$ if business activity system $\mathbf{B}$ is neutral regarding ecosystem health indicator $\mathbf{E j}$;

$\mathbf{- 2}$ if business activity system $\mathbf{B}$ is bad regarding ecosystem health indicator $\mathbf{E j}$.

$\mathbf{E j}(\mathbf{B})$ reflects the value of business activity system $\mathbf{B}$ regarding ecosystem health indicator $\mathbf{E j}$.

The following vector represents the value of business activity system $\mathbf{B}$ regarding all the ecosystem health indicators $\mathbf{E} 1, \ldots, \mathbf{E j}, \ldots, \mathbf{E n}$.

(7) $\quad \underline{E}(B)=[\mathbf{E} 1(B), \ldots, E j(B), \ldots, \operatorname{En}(B)]$

To get an aggregate picture about the value of a business activity system from the point of view of ecosystem health we should define weights that show the importance of the ecosystem health indicators. Let $\mathbf{e} \mathbf{1}, . . ., \mathbf{e j}, . . .$, en be such importance weights.

It is required that

(8) $\quad \sum$ ej $=\mathbf{1}$

The aggregate value of business activity system $\mathbf{B}$ from the point of view of ecosystem health can be calculated as follows: 
(9) $\quad \mathbf{E}(B)=\sum$ ej $\mathbf{E j}(B)$

$\mathbf{E}(\mathbf{B})$ shows the aggregate value of business activity system $\mathbf{B} .(\mathbf{1} \geq \mathbf{E}(\mathbf{B}) \geq-\mathbf{2})$

A business activity system can be considered acceptable if and only if its aggregate impact on ecosystem health is non-negative. That is

(10) $\quad \mathbf{E}(\mathbf{B}) \geq \mathbf{0}$

\section{GAIAN ETHICS}

At the level of the Earth as a whole, Gaian ethics applies to business. The Gaia theory developed by British independent scientist James Lovelock proposes that the biosphere and the physical components of the Earth (atmosphere, cryosphere, hydrosphere and lithosphere) are closely integrated to form a complex interacting system that maintains the climatic and biogeochemical conditions on Earth in a preferred homeostasis. It was named after the Greek supreme goddess of Earth. The theory is frequently described as viewing the Earth as a single organism. Lovelock defines Gaia as a complex entity involving the Earth's biosphere, atmosphere, oceans, and soil; the totality constituting a feedback or cybernetic system which seeks an optimal physical and chemical environment for life on this planet. (Lovelock 2000)

The essence of Gaian ethics is the respect for the self-regulating character and evolutionary uniqueness of the biosphere. (Fox, W. 1990) From Gaian ethics the following ethical implication can be derived for business. 
(E3) Business should not contribute to the violation of the systemic patterns and global mechanisms of the Earth.

The most important impacts what business organizations can make on the living planet include $\mathrm{CO} 2$ emission and reducing biodiversity.

Let $\mathbf{P 1}, \ldots, \mathbf{P j}, \ldots . ., \mathbf{P n}$ be living planet indicators. $(\mathbf{n}>\mathbf{1})$

$\mathbf{P i}$ ( ) is an living planet function defined as follows:

1 if business activity system $\mathbf{B}$ is good regarding living planet indicator $\mathbf{P} \mathbf{j}$;

(11) $\mathbf{P j}(\mathbf{B})=\mathbf{0}$ if business activity system $\mathbf{B}$ is neutral regarding living planet indicator $\mathbf{P j}$;

$\mathbf{- 2}$ if business activity system $\mathbf{B}$ is bad regarding living planet indicator $\mathbf{P j}$.

$\mathbf{P j}(\mathbf{B})$ reflects the value of business activity system $\mathbf{B}$ regarding living planet indicator $\mathbf{P j}$.

The following vector represents the value of business activity system $\mathbf{B}$ regarding all living planet indicators $\mathbf{P 1}, \ldots, \mathbf{P j}, \ldots, \mathbf{P n}$.

$$
\underline{\mathbf{P}}(\mathbf{B})=[\mathbf{P 1}(\mathbf{B}), \ldots, \mathbf{P j}(B), \ldots, \mathbf{P n}(B)]
$$

To get an aggregate picture about the value of a business activity system from the living planet point of view we should define weights that show the importance of living planet indicators. Let $\mathbf{p 1}, \ldots . ., \mathbf{p j}, . . .$, pn be such importance weights.

It is required that

(13) $\sum \mathbf{p j}=\mathbf{1}$ 
The aggregate value of business activity system $\mathbf{B}$ from the living planet point of view can be calculated as follows:

(14) $\mathbf{P}(B)=\sum \mathbf{p j} \mathbf{P j}(B)$

$\mathbf{P}(\mathbf{B})$ shows the aggregate value of business activity system $\mathbf{B} .(\mathbf{1} \geq \mathbf{P}(\mathbf{B}) \geq \mathbf{- 2})$

A business activity system can be considered acceptable if and only if its aggregate impact on the living planet is non-negative. That is

$$
\mathbf{P}(\mathbf{B}) \geq \mathbf{0}
$$

\section{BUSINESS SUSTAINABILITY}

We derived three principles from environmental ethics for business in order to achieve sustainability.

(E1) Business should assure natural life conditions and painless existence for animals and other sentient beings.

(E2) Business should use natural ecosystems in a proper way, that is, not damaging the health of the ecosystem during use.

(E3) Business should not contribute to the violation of the systemic patterns and global mechanisms of the Earth.

Today's mainstream business organizations are not able to satisfy these environmental principles. Usually they make a negative aggregate impact on nature. However, some alternative businesses function in a sustainable way. One prime example of these organizations is LifeGate an innovative Italian company that provides organizations and 
consumers with sustainability-oriented products and services. One of its programs is called "Zero Impact" which helps organizations to reduce and compensate their $\mathrm{CO} 2$ emissions. (http://www.lifegate.it).

Satisfying the ethical principles (E1), (E2) and (E3) can assure business sustainability in an ethically meaningful way. In a more operationalized form it means that

(16) $\quad \mathbf{A}(\mathbf{B})>\mathbf{0}$ and $\mathbf{E}(\mathbf{B})>\mathbf{0}$ and $\mathbf{P}(\mathbf{B})>\mathbf{0}$

In this case the aggregate impact of business on animal welfare, ecosystem health and the living planet is non-negative and hence business can perform its duty of not harming nature or allowing others to come to harm.

\section{References:}

Constanza, R. 1992. Toward an Operational Definition of Ecosystem Health. In R. Constanza, B. G. Norton \& B. D. Haskell (Eds.), Ecosystem Health. New Goals for Environmental Management: 239-256. Washington, D.C. \& Covelo, California: Island Press.

Five Freedoms. Animal Welfare Council. http://www.fawc.org.uk/freedoms.htm

Fox, W. 1990. Towards a Transpersonal Ecology. Shambhala Publications: Boston.

Leopold, A. 1949. A Sand Country Almanac. New York: Oxford University Press. 
Lovelock, J. 2000. Gaia: A New Look at Life on Earth. Oxford University Press:

Oxford.

Maturana, H. R. \& Varela, F. J. 1987. The tree of knowledge: The biological roots of human understanding. Shambhala Publications: Boston.

Singer, P. 1995. Animal liberation. Pimlico: London.

Zsolnai, L. 1996. Environmental ethics for business. Management Research News. 19: $9-15$. 